\title{
Experiences of Computer Science Curriculum Design: A phenomenological study
}

\author{
Art Sloan \\ Technological University Dublin, art.sloan@tudublin.ie \\ Brian Bowe \\ Technological University Dublin
}

Follow this and additional works at: https://arrow.tudublin.ie/scschcomart

Part of the Adult and Continuing Education Commons, and the Curriculum and Instruction Commons

\section{Recommended Citation}

Arthur Sloan and Brian Bowe. 2015. Experiences of computer science curriculum design: A phenomenological study. Interchange 46, 2 (2015), 121-142, DOI: 10.1007/s10780-015-9231-0

This Article is brought to you for free and open access by the School of Computer Sciences at ARROW@TU Dublin. It has been accepted for inclusion in Articles by an authorized administrator of ARROW@TU Dublin. For more information, please contact arrow.admin@tudublin.ie, aisling.coyne@tudublin.ie,gerard.connolly@tudublin.ie.

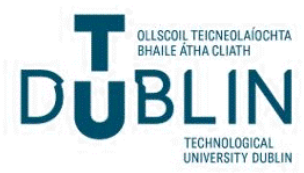


Arthur Sloan and Brian Bowe

Experiences of Computer Science Curriculum Design: A phenomenological study

Arthur Sloan

School of Computing

Dublin Institute of Technology

Kevin Street

DUBLIN 8

Republic of Ireland

Art.Sloan7@gmail.com

Brian Bowe

College of Engineering and Built Environment

Dublin Institute of Technology

Bolton Street

DUBLIN 1

Republic of Ireland

Brian.Bowe@dit.ie

\begin{abstract}
This paper presents a qualitative study of twelve computer science lecturers' experiences of curriculum design of several degree programmes during a time of transition from year-long to semesterised courses, due to institutional policy change. The background to the study is outlined, as are the reasons for choosing the research methodology. The main findings are presented and the implications of the study described. The methodology chosen was hermeneutic phenomenology. The data were the texts of interview transcripts of the twelve participant lecturers. The experiences that emerged from analysis of the data grouped naturally in identifiable and presentable themes and these themes represent the findings of the study. The findings of our study describe the computer science lecturers' lived experiences as curriculum designers, most especially in relation to institutional policy, and a new modularisation/semesteridation approach to curriculum design. Findings include the feeling lecturers have that much of the formality of curriculum design is bureaucratic, and that academics and staff do not communicate very much in relation to policy. Also, modularisation and semesterisation causes difficulty for lecturers in their designing of curricula. The findings also suggest that lecturers feel obliged to do the best they can for students. The findings lead to points of discussion that are relevant to groups and individuals associated with third-level education.
\end{abstract}

Keywords curriculum design, hermeneutic phenomenology, lived experience, policy, modularisation, semesterisation. 


\section{1: Introduction}

This research study set out to examine the experiences of lecturers who were undertaking curriculum design and in the context of tertiary-level computer science degree programmes. The investigation occurred at a time of change to curriculum design policy at their institute; specifically a move from a year-long academic calendar to a semesterised and modularised calendar, and a move from content-focused curriculum design to learning outcomes-based curriculum design. Since the changes were based on institutional policy, we wanted to investigate how the computer science lecturers experience institutional policy in relation to curriculum design, and the strategies of modularisation and semesterisation as an example of that policy.

This research follows the suggestion by Trowler (1997) of further investigation into the effects of institutional policy change on lecturers, and their experiences, as can be inferred from the work of Billing (1996) and Hennessy et al (2010). Therefore, we considered that an investigation of the experiences that computer science lecturers have of curriculum design policy and strategy would be informative and enlightening, and that curriculum design would benefit from these experiences being analysed and documented. Thus the study would shed light on some of the circumstances of computer science lecturers, in their role as curriculum designers, and in the context of dramatic change in institutional curriculum design policy. We acknowledge that the research was set in the computing department of one institute, producing findings specific to that organisation, but we feel that there is much to be learned by many readers of the outcomes of this study. We expect that the work will allow others involved in curriculum design, in any institute, to be reflective on their own issues and experiences.

Our research aimed to show how lecturers experience and understand phenomena associated with curriculum and/or module design policy and strategy, but the overall aim of this research was to see what themes emerged from the data: themes that reflected the notable instances that lecturers encounter, and some of their concerns about issues around curriculum design. The objective of the study was to be able to find implications for lecturers as curriculum designers. These implications were to come from analysis of data from interaction with a sample group of computer science lecturers. The data would provide an overall description of interpreted experiences of these lecturers from their individual descriptions of the task of module and curriculum design, through their own mental reflections on the task and the attendant experiences.

The research focused on qualitative observations of the lecturers' experiences of module design. In order to achieve the overall research objective a phenomenological approach was used to answer the following research questions:

1. How do lecturers experience curriculum design?

2. How do lecturers understand the implications of policy change for curriculum design?

3. How can the meaning that lecturers make of their experiences of curriculum design be attributed to the effects of change in curriculum design policy?

\section{2: Context of the Study}

Lecturers acknowledge the importance of the curriculum design and how it is represented by the programme documentation (Hewitt 2006) where professionalism drives the lecturer to plan modules as best they can. They understand that a great deal of the quality of a degree comes from its design (Hewitt 2006) and how the curriculum is designed will have a direct effect on the student (Diamond 2008). The curriculum designer must, at the earliest part of curriculum design, ask himself or herself what the aims and goals of the curriculum are (Forsyth et al, 1995). D'Andrea and Gosling (2001) suggest that the curriculum designer must be aware of, and amenable to, changes and improvements as they become obvious from initial design to review, over the academic years. Throughout curriculum design, lecturers have responsibilities. For example, through analysis, design, implementation and evaluation of the curriculum they set goals, plan learning experiences, select content and assess outcomes of educational programmes. These constant processes have contributed to the emergence of the structure in curriculum planning (Wiles and Bondi, 2007). Degree programmes ought to be designed to allow a student to progress over time, have feedback mechanisms, as Ramsden (1992) suggests, to allow the student to 'get a feel' for their progress, and allow them to feel secure in their learning. It is the lecturer's responsibility as a professional to provide that security (Ramsden, 1992). That responsibility ought to be shared among peers and administration of curriculum design, and usually is (Cannon and Newble, 2000), because the responsibility for the design of curricula for third-level education is considerable. 
At an institutional level, there are policies and strategies that directly affect curricula (Papatsiba, 2014), or the lecturers that design them. Often there are local or institutional policies associated with degree programmes: how they are delivered and how they are designed (Wheelahan, 2010). Related to this, Wiles and Bondi (2007) say that the structure of curriculum development has always involved process. The principles of curriculum have evolved from practice rather than enlightenment, so the theory of curriculum has followed the practice found in school (institutional) environments (Wiles and Bondi, 2007). That practice is guided by institutional policy. For Luxon and Peelo (2009), institutional policy and strategy is an important aspect of educational management, but their benefits may not transmit effectively to the teaching and learning experience of lecturers and students in lecture theatres if there is too much focus on systemic changes.

Related to institutional policy, modularisation and semesterisation can be seen as approaches or strategies for curriculum design. Modularisation of programmes involves the packaging of programme content (theory or practical) into shorter, logically self-contained units which, together, cover the content which would be covered by a conventional, year-long programme (Cornford, 1997). Morris (2000) says that modularisation and semesterisation are often treated as coterminous, but that they are actually separate phenomena: modularisation may be defined as the process by which educational awards are broken up into component parts of a more or less standard size, whereas semesterisation can be defined as a change in the pattern of programme delivery. This can be a change from year-long degree programme subjects - perhaps three terms of between eight to twelve weeks duration, to two semesters of between twelve and sixteen weeks (Morris, 2000). Brehony and Deem (2005) distinguish modularisation from semesterisation by describing modularisation in terms of a 'menu' of study options for students, and describe semesterisation as longer blocks of teaching time. University College Dublin has fitted elective modules into single semesters (Hennessey et al, 2010), and one can infer that this programme-management strategy is common among many tertiary-level institutes as changes involving modularisation and semesters have occurred in many UK universities (Brehony and Deem, 2005).

For this research there was much that we wanted to learn about curriculum design, curriculum design policy and the lecturer's participation in that task. We were clear about what we wanted to investigate, but we needed to be clear about which methodology would suit this investigation. We chose the qualitative method of phenomenology because it produced the data that informed the research questions that we posited. Those data were specific to the experiences related to the task of curriculum design. The next section considers a number of methodologies and follows the chosen methodology through its employment for data collection and analysis.

\section{3: Research Methodology}

This research was situated in a set of epistemological beliefs and assumptions of 'constructionism' (Papert in Harel and Papert 1991), which is related to the more commonly known constructivist perspective in that they both view meaning as something that is not discovered, but constructed. Constructivism gave a useful perspective since this study required a context in which to place the research questions. The research attempted to clarify lecturers' experiences in curriculum design, so constructivism, as Papert (1991) describes it - in terms of learning - fed into the context of the research.

We considered that constructivism, on its own, may not be a paradigm complete enough in which to set the research. Looking further at paradigms, Cohen et al (2000) suggest three paradigms in which education research can be situated: positivist, critical theory and interpretive. The interprevist perspective was used to set the research questions and to choose a research methodology.

Qualitative methodological approaches tend to be based on recognition of the subjective, experiential life-world of human beings and description of their experiences in depth (Patton 2002). Qualitative methods 'enable us to explore concepts whose essence is lost in other research approaches' (Bogdan and Taylor 1975, p. 5); to observe human behaviour (Bogdan and Taylor 1975) so that we can get a sense of what the participant experiences. We chose hermeneutic phenomenology as a methodology.

\section{1: Hermeneutic Phenomenology}

The broadest definition for phenomenology is that it is a theoretical point of view advocating the study of individuals' experiences because human behaviour is determined by the phenomena of experience rather than objective, physically described reality that is external to the individual (Cohen et al 2007). It can be seen as a method or methodology when 
employed to garner meanings for individuals through the analysis of their language as spoken or written (Kvale and Brinkmann 2009; Langdridge 2007).

There are two methodological strands of phenomenology: descriptive and interpretive. Descriptive was the first of the two and this philosophy was further developed to become interpretive phenomenology (Kvale and Brinkmann 2009). Interpretive phenomenology is also known as existential phenomenology and includes a version called hermeneutic phenomenology. Max van Manen (1997) has been developing the hermeneutic approach of phenomenology. Phenomenology describes how one orients to lived experience, hermeneutics describes how one interprets the 'texts' of lived experience and semiotics is used to develop a practical writing or linguistic approach to the methods of phenomenology and hermeneutics. Hermeneutic phenomenology is a human science which studies persons (van Manen, 1997). The objectivity and constructionist viewpoint of hermeneutic phenomenology made it a methodology to use for our research as it cast light on the main principle of our research questions: the experiences of lecturers as curriculum designers.

\section{2: Participants}

We set about analysing and documenting some aspects of curriculum design for several degree programmes, and wanted to involve some of the lecturers who design and deliver the modules of these programmes. We requested participation from among academic peers. We selected twelve computer science lecturers from the respondents to participate in this research. These lecturers were chosen from the School of Computing as they were academics for the degree programmes chosen, they were experienced in teaching approaches, as well as being aware of most of the aspects of curriculum design.

Of the degree programmes, three were four-year honours undergraduate programmes and two were 1-year (full time) master's degrees from the postgraduate programmes:

- BSc in Computing

- BSc in Computer Science

- $\quad$ BSc in Information Technology

- MSc in Computing (Assistive Technology)

- MSc in Computing (Information and Knowledge Management)

Four participants had graduated with $\mathrm{PhD}$ qualifications and eight were Masters graduates. Several of the lecturers had taught for many years and several had become lecturers within two years previous and who had much less teaching experience - with some overlap among these categories. They ranged in age from late twenties to late fifties. As might be surmised, the younger participants had few years of lecturing experience, the oldest had most experience, but the three oldest had been systems engineers for at least half of their careers. There were eleven males and one female.

The twelve lecturers have been teaching in a variety of learning environments including lectures, tutorials and laboratories. We ensured that there was a balance of profiles to include those:

- with substantial computer science research commitments, in that they had research groups with postgraduate students

- with substantial administrative duties - as members of School/Department management

- with substantial teaching commitments, such as 'assistant lecturers' with eighteen teaching hours per week

- who were involved in modularisation and semesterisation initiatives

- who were involved in other pedagogical developments, such as online learning

This gave the study perspectives and data from different types of lecturer within the same faculty department.

We met the twelve participants individually to talk to them ahead of the research interviews proper. We discussed the idea of curriculum design, and their role in it, broadly. We wanted to allow them to express opinion and anecdotes ahead of the investigative interviews where their experiences would be discussed. This gave us a chance to establish a relationship of trust with the interviewees so that they would be more forthcoming on their experiences in their interviews. We took notes and recordings of the discussions in those meetings. The outcome of the early meetings with each participant informed some of the questions posed in the interview schedule.

\section{3: Data Collection Methods}


The sample sizes of participants for phenomenological study are small, around seven participants, with a view to allowing the researcher to become deeply involved in the data and, therefore, the phenomenon (Connelly 2010). In data gathering for this research we chose the open, semi-structured interview technique. The aim of the interview is to have the participant reflect on his or her experiences and then relate those experiences in such a way that both participant and researcher came to a mutual understanding about the meanings of the experiences, or of the accounts of the experiences (Kvale and Brinkmann 2009). This data gathering technique would provide us data for transcript analysis. Interviewing has variations that can be used for specific qualitative research needs (Cohen et al 2007; Miles and Huberman, 1994). In our study there were twelve participants, each interviewed for an hour, approximately. There were fifteen broad, discursive questions. Three examples are:

1. What does curriculum design mean to you?

2. What was it like to design this module?

3. What was difficult about the module design?

There is a complete version of the interview schedule in Appendix 1.

The interviews produced twelve transcripts. These transcripts were analysed using hermeneutic phenomenology. The process of analysis is referred to here as 'reduction' because of its relation to the eidetic reduction of Smith et al (2009). Analysing the data yielded themes that described the lecturers' feelings, perceptions, conceptions and approaches; experiences that lecturers have as curriculum designers.

\section{4: Data Analysis Methods}

The main set of twelve interviews followed three pilot interviews. All of these interviews were then transcribed verbatim from the audio recordings and in analysing the data, qualitatively distinct themes emerged that described the lecturers' feelings, perceptions, conceptions and approaches. This process of analysis, using hermeneutic phenomenology, is referred to here as 'reduction', because of its relation to the eidetic reduction of Smith et al (2009). The themes are juxtaposed or compared to the interview questions that were used to see if and how the questions relate to themes as focal points of the study. These themes are better termed 'lived experiences' - as described by van Manen (1997), for the purpose of a phenomenological study.

\subsection{1: Writing the Transcripts}

The transcription of the recorded files began the day after the last interview. The overview of the transcript schedule is included here as this turned out to be an important part of the phenomenological analysis: we began learning about the lecturers' experiences by listening to the recorded files and writing them down - ahead of the full hermeneutic phenomenological analysis. By writing them from the recordings, we were much more 'in tune' with the participants' experiences when the analyses was performed later. As Langdridge (2007) has suggested, transcription brings the researcher 'closer to the data'. Transcript analysis is the attempt to identify the valuable data (Cresswell, 2007) and this was the next undertaking.

\subsection{2: Reflexivity and the Hermeneutic Circle}

Reflexivity describes the process in which researchers are conscious of and reflective about the ways in which their questions, methods and subject position might impact on the data or the psychological knowledge produced in a study (Langdridge, 2007). Reflection - or reflexivity - in phenomenology is important to van Manen. For him, phenomenology is a project of reflection on the lived experience of human existence (van Manen, 2007), where the reflection can be seen as being part of an investigation of the nature of a phenomenon: not an explanation for it, but a description of it as it appears in consciousness, where 'nature' is 'that which makes something what it is, and without which it could not be what it is' (van Manen, 1997). We used the principles of reflexivity and the hermeneutic circle in our analysis of the data. These were valuable techniques in this study to explicate findings from the data of the interviews with participants.

Another consideration for data analysis, where hermeneutic phenomenology is concerned, is the 'hermeneutic circle'. van Manen's hermeneutic approach of phenomenology includes, in its philosophy, that language reveals being within some historical and cultural contexts, understood by participant and researcher and through language, such as the language of the interview, moving in the hermeneutic circle between part and whole, with no beginning or end (Langdridge, 2007). We used the hermeneutic circle as a technique in our analysis of the data.

\subsection{3: Beginning the Reductions}


During the first iteration of analysis we looked for both similarities and differences among transcripts, selecting significant statements and comparing these statements in order to find cases of variation or agreement and thus grouping them accordingly. At this stage we had become familiar with the transcripts - a valuable outcome of transcription and familiarity with the conversation (Kvale, 1996). Getting a sense of the data could be described as moving into the content of the transcripts with a sense of self-trust in one's analytical process (Storey in Lyons and Coyle, 2007).

Following this, each text was broken down into more manageable units of meaning. This was achieved by removing paragraphs of text that were explanatory of the module chosen for discussion or any other tracts of text that I deemed 'general conversation'. What remained were paragraphs that described the participants' responses to the key points of each interview question and/or their digressions that had value as data.

\subsection{4: Refining the Reductions}

At this stage the twelve highlighted documents were read and reread, and more comments hand written in the margins. In the refinement/reduction of these documents, they became what we called 'quotes' documents: a long list of quotes that related to the specific experiences, feelings or personal changes of each participant. This was the core data. The analysis, at this point, could be seen in light of the hermeneutic circle (Kvale, 1996) and reflexivity (Cohen et al, 2007). We felt that this analytical effort of interpreting using the hermeneutic circle would give stronger - or more valuable - interpretations that would properly answer the research question of how lecturers experienced the task of curriculum design.

\subsection{5: Emergent Themes}

The 'quotes' documents had statements made by the participants that could be readily related to the phenomena of module design by the participants - how they experienced module design, the issues and the circumstances surrounding that job of producing a module descriptor. We saw that the statements could be related to general themes prompted by the interview questions. van Manen (1997) refers to themes as 'structures of experience', and those structures began to become apparent in the analysis notes and documents at this stage of the investigation.

We could see that some statements made by participants and their interpretations 'clustered' in relation to different aspects of the phenomena discussed by the participants and me during the interviews. As we reread all twelve of the 'hermeneutic analysis documents' we could see that it was possible to apply theme headings to statements for participants. There emerged ten themes across all participant documents, but the four themes relating to institutional policy, semesterisation and lecturers' roles have been selected and described in the next section for this article. They are:

1. How Lecturers Relate Institutional Policy to Curriculum Design

2. How Lecturers Experience the Modularisation and Semesterisation Strategies

3. A Sense of Responsibility

4. A Sense of Professionalism

\section{4: Findings}

The findings of the interviews are made up of what van Manen (1997) describes as hermeneutic phenomenological themes. Viewing the participants' experiences holistically, we could see that they spoke about their experiences in the context of pedagogy - pedagogy as a process related to the instructionalist or constructivist models (Sambrook et al, 2001). Below are the findings, in detail, of the four example themes that reveal something about the phenomena of lecturers experiences of curriculum design policy, and modularisation and semesterisation as examples of strategy related to such policy. The described interpretations are the result of the use of hermeneutic phenomenology as a methodology, as proposed by van Manen (1997). With these descriptions are some examples of transcript excerpts that relate to the corresponding themes.

\section{1: The Hermeneutic Phenomenological Themes}

4.1.1: How Lecturers Relate Institutional Policy to Curriculum Design

In the context of institutional policy, during the transition of curriculum design, Participant 1 says that curriculum designers must offer compromise to other parties, such as academic management, in how and when they complete the task of curriculum design, as well as in relation to the resources that the new curriculum design calls for: 
Participant 1: "People fight hard for their perspective and position, so you have to (negotiate)... The people who want (the change)... it's often (about) delivering compromise amongst these people as well. But that's probably the nature of the beast anyway."

Participant 1 describes the 'other parties' at this stage, and makes the point that there may be conflict among perspectives on curriculum design: governmental, industrial and educational. For the curriculum designer, catering for the different perspectives caused complexity as the educational perspective might be at odds with economic or legal mandates, for example:

Participant 1: "...that they were coming from different perspectives - for example, there might be a conflict between a government perspective, versus an industrial perspective, versus an educational perspective... it was complex in terms of how you were trying to get your message across and why it needed to be done in a particular way, and giving our experiences of dealing with these actual curricula versus someone who might be interested in getting involved in this. Or having a requirement to meet a particular legislative or economic mandate in relation to this."

Participant 1 feels that the changing circumstances of lecturers; deterioration in working conditions and not having a chance of tenure, for example, makes lecturers defensive of their positions, and that is reflected in how they deal with curriculum design: that they will design a module that will help establish their position in the faculty, and that they are willing to 'fight for' their design. Since the design of curricula directly affects lecturers who deliver the curricula, the module design task becomes important for the lecturer to consider carefully - i.e. when institutional policy affects working conditions, the lecturer looks at the effect of curriculum design. Pedagogy is a casualty of the new regime:

Participant 1: "Because of the nature of the broader picture, where (lecturers') employment has been threatened and their (conditions changed)... particularly with the policies of the government in terms of rubbishing public servants and things like that, that people have become much more defensive, and a natural consequence of defensiveness is that you're going to fight harder on your own patch... It's a conflict between that, if the overall goal, for example, dictates a particular position, and a person is threatened, particularly in the heightened positions that we're currently in, the natural consequence of that is people are going to - and rightly so - are going to defend their own positions... As I say, I think we are now in a situation where other factors, which are going to impact on the lecturers, are going to play a major role in curriculum design. And I think that it's going to be based on other factors, other than pedagogical factors, from now on."

In terms of institutional policy, Participants 2, 3 and 8 see the new approach to curriculum design to be a 'boxticking exercise'. Participant 2 describes writing the module descriptor as a task to be 'ticked off' and is concerned that the product of the exercise, the module descriptor, has no value:

Participant 2: "And you have to spend time, write something that, you hope, just ticks a box... and you may feel (that you wasted your time)... and that's always frustrating, because you're just saying, 'Well, I've (done this, but)... this isn't useful.","

Participant 2 also sees the task of writing the module descriptor for module design as extra work for a lecturer, but as just a 'rubber stamping exercise', to some extent, in order to legitimise the module designers role as a lecturer: Participant 2: “...so getting an extra task on top of it, which you can perceive as just getting a rubber stamp, in some ways, to continue doing what you're doing."

For Participant 3, the documentation of curriculum design is a report for external examiners and the programme validation panel to allow panel members to tick off required features of the programme. As such, the module descriptor is 'a box ticking exercise':

Participant 3: "(The module descriptor) is meant to be indication of what the module is about, so that the external examiners and the people on the review panel for the course, will pass the module, and will pass the document."

Participant 8 sees the documentation of learning outcomes-based curriculum design to be a 'box ticking exercise' that comes through policy making by institutional management that ignores academic quality in favour of other considerations, such as economic pressure from government offices: 
Participant 8: “...the people at the top won't (care at all) about QC (Quality Control) work. They don't care about anything else (other than student numbers and other economic factors, for example). It looks good in boxes, tick it... we've covered everything, and leave it."

4.1.2: How Lecturers Experience the Modularisation and Semesterisation Strategies Semesterisation and its modularisation of programmes forces the participants to modify their teaching, assessment and learning outcomes of year-long programmes to fit semesters, or to adopt a new approach to curriculum design for semesterisation specifically.

The experiences of participants in relation to the curriculum design strategy of semesterisation, using modularisation to manage module design, are different among the whole group. However, there are generalised experiences: reduction of time for content delivery, less student assimilation of knowledge by students, fragmentation of learning opportunities, replacement of progressive continuous assessment with 'instant' assessment (our term).

In the first year of semesterisation, Participants 2, 4 and 10 took a year-long module and split it for two semesters into two modules. They all feel that the thirteen-week semester is short and limited what they could put in the module. They find that the delivery was compromised for their modules. Participant 2 describes semester one as being worse than two, because of disproportionate content. Participant 4 and Participant 10 describe a reduction in content delivery. Participant 4 reports a change in assessment practice. Participant 10 feels that the students needed more teaching than the semester provided:

Participant 2: "I feel that the modularisation means that the (first half of the split) module is slightly worse in delivery because there's more content... Whereas before, you might have had a full year, and you could have spent more than half of the time... now you have to get that done in one semester."

Participant 4: "(There was a split) - practice in one module, and then the in-depth theory afterwards... And part of the split was the fact that we have thirteen-week modules... Modularisation, semesterisation, had a big impact on that: what can you squash in to thirteen weeks... what topics would we actually cover, had a big impact on that... And that limits how much material that you can cover, it limits what you can do in terms of designing assessments and things like that... It was short... but... you will always be limited by some amount of time... There's always going to be 'a problem', a question about how much time you have, and trying to fit in the topic into the time."

Participant 10: “...there wasn't time to consider the consequences of that split, but, when you began teaching it, you'd say (that) these students need something more out of this stand-alone module than what they were getting... there's lots of other stuff that you could do if you had a whole year to deliver a module... but (with a fourteen-week module) you have to leave out stuff."

The most obvious experience of the effect of moving from a year-long programme to a semesterised programme in the first year is the realisation of time limitations. This is exemplified by Participant 4's description: "Two or three week in, we said, 'Well, hang on a minute here, what... I don't think I'm going to get through all this stuff."

In relation to modularisation, Participant 4 is concerned that modularisation is causing fragmentation of learning experiences for students. In other words, the compartmentalisation of learning modules may separate students from continuity of learning via study of other subjects in other modules. They see a piecemeal solution, but students taking an individual module are at a learning disadvantage:

Participant 4: "Across these different modules... there are some problems with the students who are doing a single module... They don't get that (learning in one module), and... I suppose, they have to get that (learning) somewhere else... You can, kind of, do that (by) making them read bits and pieces, and, obviously, you talk about some of these things in (this module), but they wouldn't get the same depth that, obviously, the students who have done a full module, on this stuff, would get."

Participant 7 tries to avoid the fragmentation problem by talking about issues related to fragmentation with other module designers, in their capacity as Programme Chair. They suggest to the other module designers that they all use similar teaching strategies and material, so that students taking single modules do not lose out - a kind of selfcontainment of the modules: 
Participant 4: "So, for me, because I'm the Course Chair of this Master's as well, I discuss, with the other lecturers, what examples we'll be using, what types of analogies we talk about, what language we use in our assessments. And even though they are not directly linked, the words are the same, or sometimes we use the same case study. So a student who is doing two modules (gets) the benefit of it, but if the student isn't doing (both or all), they don't lose out on (a learning opportunity)."

In general, the participant lecturers find many problems with semesterisation and modularisation. For example, Participant 1 finds semesterisation to be inflexible, unforgiving and time-restrictive. A particular difficulty is that one cannot factor into the design a lecturer's absence through sickness, or some students having trouble 'keeping up' with module content during the thirteen-week delivery time could not be easily helped:

Participant 1: “...modularisation is a very inflexible setup, really... it's very unforgiving... If you... miss a week through illness... you're in trouble... there's no comeback whereas, when you had the full year... you could get them back on track fairly quickly. (Also, if a student is struggling, and)... you have only identified (the problem) in Week 8... you don't have a lot of time left to sort them, or (for them to) sort themselves out."

Participant 12 describes their concern about the reduction or removal of progressive continuous assessment due to semesteristion and modularisation and the time constraint that they impose:

Participant 12: “...practical development, for the students, of the assignments get sidelined, because they only have so much time to do an assignment."

One of the main problems that the lecturers find with semesterisation is assimilation by the students of the teaching in modules. They see the lack of time for the student to assimilate as a limitation of semesterisation. Year-long modules, with a more relaxed pace, provides more time for assimilation. Participant 4 and Participant 10 make direct comparisons between year-long and semesterised programmes. Participant 11 states that a semester is too short and that they would prefer more time per subject. They all hint at or suggest that there is a disproportionate relationship between the time allocation of one semester per module and the practicality of learning for a student:

Participant 4: “...let the stuff just float around in their heads a bit, I think that's the one, the big limitation that we've got with these thirteen-week modules: the students don't have the time... to reflect on the stuff. Assimilation... They don't have the same amount of time as, possibly, when we had these year-long modules, where the pace was probably a little bit more relaxed."

Participant 10: “(In) a year-long module, there's plenty of time (for students) to assimilate... to think about things, and to come back on (anything). Over a twelve-week period we weren't quite sure, but we were suspicious that twelve weeks wouldn't be enough time to assimilate. I think it's been proved - borne out, over the intervening years. Assimilation is a problem for students (on semesterised courses)."

“...you can't force assimilation. Human beings have a certain ability to take on board concepts - within a certain period of time. We're asking them to do however number of modules we give in a semester, (assessing) them across the board. It's becoming very difficult for the students."

"I think the twelve-week period is killing us... and...It's just not long enough to really do any meaningful assimilation of knowledge, and, then, to assess that...(is difficult)."

Participant 11: “...thirteen weeks is very short. You just simply get used to what you think you can actually fit into the module content... I went through all the thirteen weeks and looked at what I had in the content, and matched the weeks by what was in the content... (If a student is weak) I just find the thirteen weeks (causes difficulties for them)... These students don't quite get it, and it's very hard for them to recover. They miss two or three weeks - that's a quarter of the course. That's 25\% of the course! Wow! That's quite substantial."

"If I had my choice, thirteen weeks; it's just not long enough."

4.1.3: A Sense of Responsibility

There is a strong sense of responsibility among the lecturers in their role as curriculum designers. They acknowledge the autonomy of their curriculum design, and take responsibility for the task.

Participant 3 and Participant 10 find that there is quite complete autonomy given to lecturers in designing modules Participant 3 finds that this makes module design easier: 
Participant 3: “...when you're designing a module, in (our institute) anyway, you have a lot of autonomy around the module... there is a lot of trust placed in the lecturer, that they know what they're doing, and they know what they are talking about... It makes the modules easier to write, because there isn't a lot of peer review."

Participant 10: “... There was a lot left to individual lecturers.”

Participant 7 also acknowledges the autonomy, and links that autonomous design to a personal responsibility to provide effective learning outcomes for students, through proper curriculum design:

Participant 7 "I have a lot of say over what happens in terms the syllabus or module content, whereas, in terms of the learning outcomes, I know I have a responsibility to ensure that the students hit all of those learning outcomes - provided I'm teaching (on) a module (where) the learning outcomes are design correctly."

The sense of responsibility makes some participants want change in module and curriculum design for the greater good of curriculum design, as Participant 3 says:

Participant 3: "I definitely think there's a few things we could improve on."

Participant 7's feeling of responsibility is mirrored by Participant 6's feeling of responsibility to the student:

Participant 6: “...I think that's our final responsibility - to them (the students).”

\subsection{4: A Sense of Professionalism}

There is a strong sense of professionalism among the lecturers in their role as curriculum designers. They acknowledge that their curriculum design may extend their duties as lecturers. The feeling of professionalism is summarised by Participant 4: "...you, kind of, do the best job that you can do..."

Participant 7 describes a clear sense of duty to the students; to provide them with well-designed programmes and well taught modules:

Participant 7: "We're here, as an Institute of Technology, to support our students that are paying our salaries... I feel I have a duty to them, to give - (and) to create a good quality product."

Speaking for many lecturers of the School of Computing, Participant 11 says they can see that there is a professionalism among School of Computing lecturers that often takes them 'beyond the call of duty' if the extra effort will help in teaching and the welfare of the student body. Those efforts include features of modules that lecturers 'design in', but those efforts sometimes cause stress or anxiety among the lecturers who make them:

Participant 11: "There's a professional willingness (in the people here)... to do things. If it affects their teaching and their performance in front of a class, most good lecturers will say, 'OK, I'll put up with that'... And that's and that's part of our problems, to be quite honest! (Laughs) That we are willing to do that... (There is stress and anxiety amongst the lecturing staff) because most staff would be keen to do that... You still have to get that feedback to the student. You still have to be looking out for students who need extra help, and you can't turn round and say, 'Well, sorry, I can't do that anymore.,'

\section{5: Discussion of the Findings \\ 5.1: Relating Institutional Policy to Curriculum Design}

Lecturers' conception of institutional policy that affects curriculum design is that those policies are directives that ought to be obeyed. They may be obeyed willingly or unwillingly - for example, Participant 1 finds that agreement on this type of policy is based on compromise, Participant 3 finds this type of policy to be necessary administration, but, along with Participants 2 and 8, suggests that conformity to this policy is 'box-ticking'. This is similar to the workaday nature of curriculum design process, described in terms of process and filling a need (Gagne et al 2005), and on the basis of resources (Forsyth et al, 1999).

Irish lecturers may be defensive of themselves in recent times, against institutional policy, due to the demands from them for reform of curricula, being micro-managed and becoming stressed, yet being vilified in the press during 2011 (MacLaren, 2012). The negative attitude of some lecturers toward institutional policy is attributable to the culture of suspicion of academics towards institutional management, as described by D'Andrea and Gosling (2005). Trowler 
(1997) describes policy imposition on lecturers that make them negatively disposed to new policy. The findings suggest that the participants feel that they have had this curriculum design policy change placed upon them, and their general reaction is passive - much like the situation and reaction described by Trowler (1997). There needs to be improved communication and negotiation between institute management and academic staff - with compromise on both sides. This could be instigated by having large-group meetings between management and academics prior to any fundamental change of practice at an institute.

\section{2: Experiencing the Modularisation and Semesterisation Strategies}

It was apparent that semesterisation, sometimes confused by the participants (or assimilated with) modularisation, was an important issue. The experiences of participants in relation to modularisation - semesterisation properly - on module design, are different hermeneutically, but remain negative. The terms cited in discussion that were repeated by several participants were 'inflexible' and 'unforgiving'. For example:

Participant 1: “...modularisation is a very inflexible setup, really... it's very unforgiving...

Other terms used by the participants in relation to semesterised modules are 'short' (in time) and 'constraining'. Six of the respondents stated specifically that the lack of teaching time of a semester meant that there was limited time for students to assimilate knowledge. The problems of student assimilation, due to time constraint, have been identified by Gagne et al (2005) and by Harvey and Knight (1995). Cornford (2006) suggests that the reason students do not retain skills 'securely learned' (p.243) is due to the concentrated nature of the design modules on modularised programmes, and the little time (my emphasis) that a module affords the student for assimilation. He also reports inadequate prerequisite knowledge of students, on preceding modules, due to modularisation (Cornford, 2006).

The advantages of modularisation for students include study flexibility (Billing, 1996; Cornford, 1997; Hennessy et al, 2010; Lindsay et al, 2002), student choice (Billing, 1996; Cornford, 1997; Lindsay et al, 2002; Morris, 2000) and improved economy and efficiency (Billing, 1996; Cornford, 1997; Lindsay et al, 2002; Morris, 2000).

The most reported disadvantages of modularisation is fragmentation of programmes (Billing, 1996; Lindsay et al, 2002; Morris, 2000). This is described as fragmentation of units of knowledge by Cornford (1997). There is a solution to the fragmentation problem suggested by Cornford (1997), which is to 'design out' (my term) fragmentation in the curriculum design stage. The increase in workload for students, due to modularisation can be designed out in the curriculum design stage (Lindsay et al,2002). The symptoms of this type of fragmentation are described by five of the twelve participants, in relation to their modules.

O'Connor (2006) describes a case where modularisation for semesterisation can be imposed rapidly on a programme, with little forward planning and inadequate prior knowledge of the importance of programme learning outcomes. Semesteristion and its modularisation of programmes force curriculum designers to modify their teaching, assessment and learning outcomes (O'Connor et al, 2011). They do not say explicitly, in their paper, how problematic semesterisation is, but the context of their writing construes management of fragility in module design and attendant problems.

The findings show that the participant lecturers find semesterisation to be problematic as a curriculum design idea. This means that the participants dislike semesterisation as a design idea and find it to have negative consequences beyond curriculum design - i.e during teaching and assessment. The participants do not value the semesterisation design module pedagogically, but a few participants concede that they can understand the model from an administrative perspective.

The participants describe an increase in workload, due to modularisation and semesterisation. This increase in workload for lecturers, as an effect of modularisation and/or semesterisation, is reported by Trowler (1997). Semesterisation, rather than modularisation, is the cause for increased workload, according to Morris (2000). This may account for the experiences of lecturers who participated in this study, as each of them designed and delivered modularised programme modules in a semesterised structure. Where the increase in workload is problematic for lecturers, an accommodation for increased workload might be for institute management to employ administrative staff among groups of academics locally, to help them in spreading their workload until the semesterised programmes become established.

\section{3: Lecturers' Sense of Responsibility}


In the findings a sense of responsibility is reflected in the nature of the task of curriculum design. The participants are aware of the effect their curriculum design efforts have on quality of the programme modules, and they aware of the autonomy they have as curriculum designers. For example, Participants 3, 4 and 10 describe being left to get on with the task of designing their modules. There is no indication that this is a problem - in fact Participant 3 sees this as an advantage. Autonomy in curriculum design can foster a commitment to curriculum innovation in lectures who design their own modules (Higham, 2003). For some of the participants of this study that autonomy did foster a commitment to curriculum quality and/or innovation.

The participants care a great deal about their involvement in the module design process and about producing a valuable, quality document. The lecturers' caring about 'getting it right' in terms of curriculum design is less about being seen to be able to do a good job on the design than about preparing a module that the students will find useful and fulfilling. Fitzmaurice (2010) has described this attitude of caring and responsibility of lecturers' in curriculum delivery. In some of the participant lecturers' interviews the caring responsibility towards students, in curriculum delivery, is clear. This is reflected in their sense of responsibility toward their module designs. Dewey states that teachers have a duty of responsibility to their students and, as educators, teachers are providing knowledge and forming attitudes that become part of the fabric of society (Dewey in Flinders and Thornton, 2013). This can be compared to the lecturers' realisation that they are preparing computer science students to be the programmers and systems analysts of the computing industry, post-graduation, as described by Zendler et al (2012). This is part of their motivation for teaching as well as they can, and for designing curricula as well as they can.

The lecturers realise that their module designs have a direct effect on what students learn, and they are concerned about that fact. The curriculum preparations which preoccupy the lecturers equate to the 'conditions' for optimising student learning described by Gagne et al (2005), which is the main principle of the rationale for curriculum design. Lecturers are often prepared to go beyond their duties in curriculum design if they feel that it will help students, as described by Participant 11. Even if the effort makes the lecturer overworked, those lecturers will accommodate the student.

\section{4: Lecturers' Sense of Professionalism}

In the findings a sense of professionalism is reflected in the fact that lecturers are aware of the importance of their design and place value on their module design, design document (module descriptor) and the things in it - such as aims, learning outcomes and content. Their sense of professionalism means that they take pride in their work:

Participant 4: “...you, kind of, do the best job that you can do..."

Trowler (2008) has investigated culture in education and describes academics motivated to develop curricula to a high standard. Implicit in this is the principle of lecturers taking pride in their work. Lecturers' sense of professionalism means they are inclined to improve all aspects of a programme, mainly for the benefit of students - as is the motivation in relation to their sense of responsibility.

van Manen has described 'reflection on action' where a teacher can think about what he or she has done: 'Thus pedagogical reflection on action serves to make subsequent action more mindful and tactful' (van Manen, 1991; $p$. 117). In other words, a teacher can change their ideas on academic work (especially curriculum design) based on their self-reflection - the sort of self-reflection related to a sense of professionalism. The study shows that this does occur - sometimes.

Lecturers' senses of responsibility and professionalism ought not to be underestimated by institute management when considering curriculum design and innovation. The need for lecturers to do their best for students ought to serve as a basis for negotiation between management and academics in curriculum design initiatives.

\section{6: Conclusions}

Tertiary programme curricula are often developed at an institute following missives from institutional management. These missives are often influenced by institutional policy. The tasks of curriculum development and curriculum design fall to academic groups and individual lecturers, in some instances. This research set out to examine computer science lecturers' experiences of curriculum design from institutional policy in the context of the tertiary education system. The research was set in the computing department of our own institute, and our findings represent the experiences of our peers, but we hope that any person involved in curriculum design will gain insight to issues of 
curriculum development and find that the outcomes of our study prompts them to think about their own curriculum design experiences more radically.

Our research began with reading about the situatedness of lecturers in curriculum design, and having informal discussions with academics about this situatedness. The research proceeded with an investigation of computer science lecturers' experiences of curriculum design, focusing on institutional policy in relation to curriculum design, and the strategies of modularisation and semesterisation, as an example of that policy. This included the analysis of data and documentation of findings using the qualitative methodology of hermeneutic phenomenology. This research has brought to the fore the feelings and meaning-making that lecturers, as module designers, have and do. These experiences have not been formally considered previously by academic management or the lecturers themselves.

The findings highlight the professional attitude that lecturers have toward their duty as teachers and as module designers. They also highlight lecturers' personal understanding of curriculum and module design, and the contexts in which their curriculum design experiences are set. For most of the lecturers, institutional policy that affects curriculum design constitutes directives that ought to be obeyed - willingly or unwillingly. Lecturers feel subject to policies that are owned by management, and they feel obliged to conform to policy directives. Most participant lecturers are negatively disposed to semesterisation. The participants' experiences of semesterisation vary from restrictive to hateful. The main experience is that the twelve-to-fifteen week schedule of a semester has the effect of limiting students' assimilation of knowledge, limiting/restricting variation in assessment methods and several other undesirable effects on student groups. From a design perspective, lecturers find that they are forced to arrange teaching and assessment in a restrictive pattern that matches the restrictive learning schedule.

One can infer from the findings that one cannot take curriculum or module design for granted. One cannot assume that, as an academic or a programme administrator, one can predict the issues and shortcomings of curriculum design or ignore them. Being involved in curriculum design for the sake of teaching and learning is experienced as a very personal process, rooted in a collegial context and connected with a sense of professionalism. Thus the personal and the professional have to be considered together and the phenomena of curriculum design are important in terms of contextualising lecturers' duties as curriculum designers.

It may be obvious to say that an important link is between a lecturer's situatedness in curriculum design and the issues that affect his or her experiences of curriculum design, but this research study establishes that link to accentuate the value of knowing much more about it.

\section{7: References}

Billing, D. (1996). Review of Modular Implementation in a University, Higher Education Quarterly, 50(1): $1-21$

Bogdan, R., \& Taylor, S. J. (1975). Introduction to Qualitative Research Methods: A phenomenological approach to the social sciences, New York: Wiley

Brehony, K. J., \& Deem, R. (2005). Challenging the Post-Fordist/Flexible Organisation Thesis: The case of reformed educational organisations, British Journal of Sociology of Education, 26(3): 395-414

Cannon, R. \& Newble, D. (2000). A Handbook for Teachers in Universities and Colleges: a guide to improving teaching methods, $4^{\text {th }}$ Edition, London: Kogan Page

Cohen, L., Manion, L., \& Morrison, K. (2000). Research Methods in Education, (5 ${ }^{\text {th }}$ ed), Abingdon: Routledge

Cohen, L., Manion, L., \& Morrison, K. (2007). Research Methods in Education, ( $6^{\text {th }}$ ed), Abingdon: Routledge

Connelly, L. M. (2010). What is Phenomenology? MEDSURG Nursing, 19(2), 96-100 
Cornford, I. R. (1997). Ensuring Effective Learning from Modular Courses: A cognitive, Journal of Vocational Education and Training, 49(2): 237-251

Cresswell, J. W., (2007). Qualitative Inquiry and Research Design: Choosing Among Five Approaches, $2^{\text {nd }}$ Edition, London: Sage Publications Ltd

D'Andrea, V., \& Gosling, D. (2001). Joining the Dots: Reconceptualising educational development, Active Learning in Higher Education, 2(1), 64 - 80

Dewey, J. (2013). My Pedagogic Creed. In Flinders, D.J. \&Thornton, S.J. (Eds), The Curriculum Studies Reader, $\left(4^{\text {th }}\right.$ ed $)$, New York: Routledge

Diamond, R.M. (2008). Designing and Assessing Courses and Curricula: A practical guide, New York: John Wiley and Sons, Inc

Fitzmaurice, M. (2010). Considering Teaching in Higher Education as a Practice. Teaching in Higher Education, 15(1): 45-55

Forsyth, I., Jolliffe, A. \& Stevens, D. (1999). Planning a Course: Practical strategies for teachers, lecturers and trainers, $2^{\text {nd }}$ Edition, London: Kogan Page Ltd

Gagne, R.M., Wagner, W.W., Golas, K.C., \& Keller, J.M. (2005). Principles of Instructional Design, (5 ed.), Belmont: Wadsworth

Harvey, L. \& Knight, P. T. (1996). Transforming Higher Education. Buckingham: SRHE and The Open University Press

Hennessy, E., Hernandez, R., Kieran, P., \& MacLoughlin, H. (2010). Teaching and Learning Across Disciplines: Student and staff experiences in a newly modularised system, Teaching in Higher Education, 15(6): 675-689

Hewitt, T. W. (2006). Understanding and Shaping Curriculum: What we teach and why, Thousand Oaks: SAGE Publications Inc

Higham, J. (2003). Curriculum Change: A study of the implementation of General National Vocational Qualifications, The Curriculum Journal, 14(3): 327-350

Kvale, S. (1996). InterViews: An introduction to qualitative research interviewing. Thousand Oaks: Sage

Kvale, S., \& Brinkmann, S. (2009). InterViews: Learning the Craft of Qualitative Research Interviewing, $\left(2^{\text {nd }}\right.$ ed.), Thousand Oaks: SAGE Publications Inc

Langdridge, D. (2007). Phenomenological Psychology: Theory, research and method, New Jersey: Pearson Education, Ltd

Lindsay, R., Breen, R., \& Paton-Saltzberg, R. (2002). Pedagogic Research and Evidence-Based Management, Psychology Teaching Review, 10(1): 20-30

Luxon, T., and Peelo, M. (2009). Internationalisation: Its implications for curriculum design and course development in UK higher education, Innovations in Education and Teaching International, 46(1): 51-60 
MacLaren, I. (2012). The Contradictions of Policy and Practice: Creativity in higher education, London Review of Education, 10(2): 159-172

Miles, M. B., \& Huberman, A. M. (1994). Qualitative Data Analysis: An expanded sourcebook, (2 ${ }^{\text {nd }}$ ed.), London: SAGE Publications Ltd

Morris, H. (2000). The Origins, Forms and Effects of Modularisation and Semesterisation in Ten UK-Based Business Schools. Higher Education Quarterly, 54(3): 239-258

O'Connor, C.M. (2006). Designing Curriculum and Assessment to Promote Effective Learning in Chemistry in Higher Education, Level 3. Retrieved from:

http://level3.dit.ie/html/issue4/christine_oconnor_paper_2/oconnor2_1.htm

O'Connor, C.M., McDonnell, C., Ennis, P., \& Shoemaker, L. (2011). Now For The Science Bit: Implementing community-based learning in chemistry, Education and Training, 53(2/3), 218 - 236

Papatsiba, V. (2014). Policy Goals of European Integration and Competitiveness in Academic Collaborations: An examination of joint Master's and Erasmus Mundus programmes, Higher Education Policy, 27(1): 43-64

Papert, S. (1991). Preface. In I. Harel, I and S. Papert, (Eds.), Constructionism: Research reports and essays 1985-1990, New York: Ablex Publishing Corp

Patton, M.Q. (2002). Qualitative Research and Evaluation Methods, ( $3^{\text {rd }}$ ed.), London: SAGE Publications, Ltd

Ramsden, P. (1992). Learning to Teach in Higher Education, Abingdon: Routledge

Sambrook, S., Geertshuis, S., \& Cheseldine, D. (2001). Developing a Quality Assurance System for Computer-based Learning Materials: Problems and issues, Assessment and Evaluation in Higher Education, 26(5), $417-426$

Smith, J. A., Flowers, P. \& Larkin, M., (2009). Interpretative Phenomenological Analysis: Theory, Method and Research, Sage Publications Ltd

Storey, L. (2007). Doing Interpretive Phenomenology Analysis. In: A. Lyons and E. Coyle, (Eds.,) Analysing Qualitative Data in Psychology: A practical and comparative guide. London: Sage Publications Ltd

Trowler, P. (1997). Beyond the Robbins Trap: Reconceptualising academic responses to change in higher education (or... quiet flows the don?) Studies in Higher Education, 22(3), 301-318

Trowler, P. (2008). Cultures and Change in Higher Education: Theories and practice, Basingstoke: Palgrave van Manen, M. (1991). The Tact of Teaching, The Meaning of Pedagogical Thoughtfulness, New York: State University of New York

van Manen, M. (1997). Researching Lived Experience: Human Science for an Action Sensitive Pedagogy, $\left(2^{\text {nd }}\right.$ ed.), Ontario: University of Western Ontario, The Althouse Press 
van Manen, M. (2007). Phenomenology of Practice, Phenomenology and Practice, 1(1), 11-30

Wheelahan, L. (2010). Why Knowledge Matters in Curriculum: A Social Realist Argument, New York: Routledge

Wiles, J.W., \& Bondi, J.C. (2007). Curriculum Development: A guide to practice, $\left(7^{\text {th }}\right.$ ed.), New Jersey: Prentice Hall

Zendler, A., McClung, O. W., \& Klaudt, D. (2012). Content and Process Concepts Relevant to Computer Science Education: A cross-cultural study, International Journal of Research Studies in Computing, 1(2): $27-47$ 


\section{APPENDIX 1 \\ Interview Schedule}

The lecturer, having chosen one course module previously designed by them for discussion, would have received a list of aspects for discussion. These aspects would have been chosen by the researcher based on issues arising from the literature review AND the previous discussions with participants. There follows fourteen broad, discursive questions for the phenomenological interviews:

1. Please describe briefly the module which you have chosen as the one that you have designed.

2. How did you go about designing this module? (Looking for a description in terms of:

How learning outcomes were written

How assessment was developed

How teaching and learning was included

and with consideration of:

Who was involved

Documents that might have been used

and whether there was any evaluation/feedback by anybody)

3. Why do/did you design your module(s) this way?

4. What was it like to design this module?

5. What was difficult about the module design?

6. Do you use this process with all modules?

7. What did you learn from your designing of the module(s)?

8. How do you consider the student in your module design?

9. How did the process of your module design affect the implementation of the module?

10. What, if anything, would you do differently in a future module design?

11. Are you happy with the curriculum design process?

12. Are you proud of your module design?

13. Do you feel that you have changed personally due to the design experience?

14. Is there anything you wish to add? 